\title{
Synthesis of Periodic Mesoporous Organosilica by Microwave Heating
}

\author{
Sang-Soon Yoon, Won-Jin Son, Kalidas Biswas, and Wha-Seung Ahn* \\ Deparment of Chemical Engineering, Inha Unwersity, Incheon $402-751$. Korea. ${ }^{\times}$E-mail: whasahnainha.achr \\ Received October 23. 2007
}

\begin{abstract}
A periodic mesoporous organosilica material was synthesized by microwave heating (PMO-M) using 1,2bis(trimethoxysilyl)ethane as a precursor in a cationic surfactant solution, and textural properties were compared with those of the product produced by conventional convection heating $(\mathrm{PMO}-\mathrm{C})$. These synthesized materials were characterized using XRD. TEM/SEM. $\mathrm{N}_{2}$ adsorption isothern. ${ }^{29} \mathrm{Si}$ and ${ }^{13} \mathrm{C}$ NMR. and TGA. which confinmed their good structural orders and clear arrangements of uniform 3D-clannels. Synthesis time was reduced from $21 \mathrm{~h}$ in PMO-C to 2-4 h in PMO-M. PMO-M was made of spherical particles of 1.5-2.2 $\mu \mathrm{m}$ size, whereas PMO-C was made of decaoctahedron-shaped particles of $c a .8 .0 \mu \mathrm{m}$ size. Effect of synthesis temperature. time. and heating mode on the PMO particle morphology was examined. The particle size of PMO-M could be controlled by changing the heating rate by adjusting microwave power level. PMO-M demonstrated improved separation of selected organic compounds conpared to $\mathrm{PMO}-\mathrm{C}$ in a reversed phase HPLC experiment. Ti-grafted PMO-M also resulted in higher conversion in liquid plase cyclohexene epoxidation than by Ti-PMO-C.
\end{abstract}

Key Words : Periodic mesoporous silica. Microwave. HPLC. Ti-grafting. Epovidation

\section{Introduction}

Mesoporous molecular sieves are composed of ordered uniform pores of $20-100 \AA$ range and are effective in transforming large organic molecules. ${ }^{1,2}$ These materials can be prepared using surfactant molecules as a structure directing agent. around which, dissolved silicate ions form a micelle and condensed to a mesoporous material. Organic functionalization on the mesoporous materials can be conducted with their surface modified with various organic functional groups by post-synthetic grafting. ${ }^{3,4}$ or by employing a direct synthetic approach in which TEOS (tetraethylorthosilicate) is combined with a organosilane compound by sol-gel methods. ${ }^{5,6}$

Recently, a new type of periodic mesoporous organosilicas (PMOs) containing bridge-bonded organic groups ( $-\mathrm{CH}_{2}$ $\left.\mathrm{CH}_{2}-{ }^{7.9}-\mathrm{CH}=\mathrm{CH}-{ }^{10,11} \mathrm{C}_{6} \mathrm{H}_{4}{ }^{12}\left(\mathrm{C}_{6} \mathrm{H}_{4}\right)_{2}{ }^{13}\right)$ directly integrated into the silica framework was synthesized by several groups. PMOs have attracted much attention because new catalytic and adsorptive functions can be assigned to them by introducing various organic groups directly bonded to the silica host. $^{7.18}$ PMOs can be crystallized to single crystal-like uniform particles. whilst purely inorganic mesoporous silica materials usually have no definite shape. In addition. a large fraction of organic component in its composition can also prove useful in controlling hydrophobicity needed for the adsorption of non-polar organic molecules in chromatography or in liquid phase organic reactions.

It is known that hydrothermal synthesis of inorganic materials using nicrowave heating promotes nucleation and can reduce synthesis time and particle size significantly in comparison with the conventional convection heating method. Zeolite $\mathrm{Y}_{;}^{19} \mathrm{ZSM}-5,{ }^{31} \mathrm{AlPO}_{4}-5,{ }^{21}$ Ti-grafted MCM41.23 and $\mathrm{Zr}$ incorporated SBA-16 ${ }^{23}$ were synthesized using microwave heating. In addition. uniform internal heating achieved by rapid rotation of water molecules induced by the microwave irradiation can result in particles with more uniform size distribution. We can anticipate PMOs prepared by microwave heating method to have uniform smaller particles, which will be advantageous either in liquid phase catalytic reactions or in chromatographic separation by diminishing the diffusion resistances involved in each process.

In this work, a PMO containing homogeneous ethane groups was synthesized using microwave heating and its particle properties were compared with the one prepared by conventional oven heating. The effect of microwave power, synthesis temperature. time, and heating mode on particle morphology was examined. Finally. PMOs obtained were tested as a HPLC column material and as a catalyst for cyclohexene epoxidation after titanium grafting.

\section{Experimental}

Synthesis of hybrid mesoporous materials. 1,2-Bis(trimethoxysilyl)ethane (BTME, 96\%). hexadecyl-trimethylanmonium chloride $\left(\mathrm{C}_{16 \mathrm{TMACl}}\right)$, hydrochloric acid $(37 \%)$, ethanol $(99.5 \%)$. mesity lene $(97 \%)$ and cyclohexene $(99 \%)$. hydrogen peroxide $\left(\mathrm{H}_{2} \mathrm{O}_{2}, 30 \mathrm{wt} \%\right)$, titanium(IV) isopropoxide $(97 \%)$ and acetonitrile $(99.93 \%)$ were obtained from Aldrich and used as received.

Synthesis of PMO was carried out in molar ratio of 1 BTME: $0.91 \mathrm{C}_{16}$ TMACl: $2.28 \mathrm{NaOH}: 336 \mathrm{H}_{2} \mathrm{O}$ according to the procedure by Inagaki et $a{ }^{8}{ }^{8}$ The surfactant and $\mathrm{NaOH}$ were added to water in a polypropylene bottle and vigorously stirred with mild heating until it becomes clear. After introducing BTME dropwise under nitrogen, the mixture was stirred for $19 \mathrm{~h}$ at $25^{\circ} \mathrm{C}$. This mixture was then 
transferred to a $200 \mathrm{~mL}$ Teflon vessel for microwave heating. The microwave instrument used was a CEM MDS2100 model equipped with a fiber optic temperature probe and a pressure controller. which was capable of an adjustable power output. The sample was quickly heated to the target synthesis temperature and subsequently adjusted to constant $50 \%$ power level to maintain isothermal condition. Synthesis was carried out at temperatures of 95.115 , and $135^{\circ} \mathrm{C}$ for 4 h. Heating time was also varied between $30 \mathrm{~min}$ to $6 \mathrm{~h}$ at a fixed temperature of $115^{\circ} \mathrm{C}$. To study the effect of heating rate. microwave heating power (maximum $950 \mathrm{~W}$ at 2450 $\mathrm{MHz}$ ) was adjusted to $100,50.25$. and $15 \%$ of the full power until the target synthesis temperature was attained. and subsequently adjusted to constant $50 \%$ power for $4 \mathrm{~h}$ at $115^{\circ} \mathrm{C}$. The precipitates obtained were filtered. washed with distilled water. and dried at room temperature. After refluxing $1 \mathrm{~g}$ sample of the as-synthesized PMOs in $3.8 \mathrm{~g}$ of $37 \mathrm{wt}$ $\% \mathrm{HCl}$ in $150 \mathrm{~mL}$ ethanol for $6 \mathrm{~h}$ at $50^{\circ} \mathrm{C}$, it was filtered with ethanol and dried for future use. A PMO sample (PMOC) was also prepared in a convection oven kept at $95^{\circ} \mathrm{C}$ for 21 h without stirring. for comparison.

Characterization. The structural arrangement in PMOs was verified by X-ray diffraction using Ni-filtered $\mathrm{CuK}_{\alpha}$ radiation (Rigaku model D/Max-3C). Morphology was examined by TEM (Jeol model JEM-200CX) and SEM (Hitachi. X-650). The specific surface area and average pore diameters were determined by $\mathrm{N}_{2}$ physisorption at liquid nitrogen temperature using a Micromeretics ASAP 2000 automatic analyzer. The surface area was determined by BET method and the pore size distribution was calculated by the Barrett-Joyner-Halenda (BJH) method using the desorption branch of the isotherm. Prior to the measurements. PMOs were vacuum degassed at $383 \mathrm{~K}$. TGA (Mettler Toledo TGA/SDTA $85 \mathrm{l}$ ) was performed at a heating rate of $10^{\circ} \mathrm{C} / \mathrm{min}$ up to $800^{\circ} \mathrm{C}$ in a nitrogen flow.

The ${ }^{79} \mathrm{Si}$ and ${ }^{13} \mathrm{C}$ NMR spectra were recorded on a Bruker Advance II (500 MHz) spectrometer. UV-Vis diffuse reflectance spectroscopy was performed under ambient conditions using dehydrated $\mathrm{MgO}$ as a reference in the range of 190 $600 \mathrm{~nm}$ on a Varian CARY 3E double beam spectrometer.

HPLC column test. C-18 modification on the PMO samples was carried out for a reversed phase application. For this purpose. $1 \mathrm{~g}$ of PMO. $0.6 \mathrm{~mL}$ of pyridine and $6 \mathrm{~mL}$ of xỵlene were put into a small round bottom flask with a reflux condenser and stirred. Subsequently. $0.4 \mathrm{~g}$ of chlorodimethy loctadecylsilane was added and stirred at $100^{\circ} \mathrm{C}$ for $5 \mathrm{~h}$. The product was filtered and washed with toluene. THF, and methanol. and dried. For trimethylsilylation capping. $1 \mathrm{~g}$ of the dried product $0.6 \mathrm{~mL}$ of pyridine. $6 \mathrm{~mL}$ of xylene. and $0.2 \mathrm{~mL}$ of chlorotrimethylsilane were mixed and stirred at $100^{\circ} \mathrm{C}$ for $3 \mathrm{~h}$, followed by filtering. washing, and drying as before. A micro-colunn $(0.5 \mathrm{~mm} \mathrm{I.D.} \times 300 \mathrm{~mm})$ was packed with the surface-treated PMO samples and examined for their chromatographic performances in HPLC

Titanium grafting and cyclohexene epoxidation. Titanium grafting was conducted inside a glove box under nitrogen enviromment. A desired amount of titanium(IV) isoprop- oxide ( $\mathrm{Ti} / \mathrm{Si}=2 \mathrm{~mol} \%$ ) was dispersed in $150 \mathrm{~mL}$ of isopropyl alcohol ( $99.7 \%$, Merck) and mixed with $1 \mathrm{~g}$ of PMO samples under vigorous stirring for $3 \mathrm{~h}$ at ambient temperature. The solid was filtered. washed with isopropyl alcohol, and dried at ambient temperature ovemight

The catalytic properties of the Ti-grafted samples were tested for the liquid phase cyclohexene epoxidation using $\mathrm{H}_{2} \mathrm{O}_{2}$ as an oxidant. Reactions were carried out under vigorous stirring in a two-neck pyrex round bottom reactor equipped with a condenser and a themometer by mixing 33 mimol substrate, $10 \mathrm{mmol} \mathrm{H}_{2} \mathrm{O}_{2}$ (30 int \%. Aldrich). $20 \mathrm{~mL}$ acetonitrile (solvent), and $0.2 \mathrm{~g}$ catalyst at $333 \mathrm{~K}$ for $3 \mathrm{~h}$. The products were analyzed by using a HP 5890 series II GC equipped with a Supelco Nukol ${ }^{\mathrm{TM}}$ fused silica capillary colunm with a FID.

\section{Results and Discussion}

The XRD patterns of PMO samples prepared are shown in Figure 1. XRD patten of $\mathrm{PMO}-\mathrm{C}$ in (a) (i) corresponds to those attributed to a cubic symmetry with an intense (120) peak accompanied by the minor (200) and (112) peaks between 2 theta values of $1.5-2.0^{8}$ Those of PMO-M samples synthesized by microwave heating at different temperatures for 4 h in (a) (ii-iv) also clearly show the characteristic (120) peak but minor peaks are rather indistinct, which could be partly due to smaller particle size of PMO-M (see later). As was shown in (b), the plot of (120) peak intensity in the PMO-M samples prepared at $115^{\circ} \mathrm{C}$ against microwave irradiation time indicates that it takes longer than $2 \mathrm{~h}$ irradiation to have a PMO-M material with good structural order. It is noteworthy in that it took $2 \mathrm{l} \mathrm{h}$ to synthesize PMO-C sample by conventional heating. while it only took $4 \mathrm{~h}$ to synthesize PMO-M by microwave heating. TEM pictures in (c) show clear arrangements of uniform mesopores in $\mathrm{PMO}-\mathrm{M}$.

$\mathrm{N}_{2}$ adsorption-desorption isothems of the PMO-M samples are compared in Figure 2. which all show type IV isotherms with hysteresis loops present at relative pressures in between 0.3 and 0.8 . Corresponding textural properties are summarized in Table 1. The textural property values of the PMO-C (799 m-2. 28 A) matched very well with those reported by Inagaki et $a l^{7}\left(770 \mathrm{~m}^{2} / \mathrm{g}, 29 \AA\right.$ ) but PMO-M samples had their pore diameters (32-39 $\AA$ ) and pore volumes $\left(0.94-1.09 \mathrm{~cm}^{3} / \mathrm{g}\right)$ somewhat larger than those of PMO-C (28 A. $\left.0.79 \mathrm{~cm}^{3} / \mathrm{g}\right)$ accompanied by $\mathrm{ca} .3-5 \%$ reduction in surface area: as the synthesis temperature for PMO$\mathrm{M}$ increased gradually, both pore volume and average pore diameter increased concurrently. The PMO-M synthesized at $115^{\circ} \mathrm{C}$ for $6 \mathrm{~h}$ was partially collapsed in structure. This phenomenon of diminished crystallinity in PMO-C after prolonged microwave heating may be a consequence of different microwave energy absorbance characteristics of the organic and inorganic portions in PMO-C

${ }^{29} \mathrm{Si}$ MAS NMR of these materials confirmed that Si-C covalent bond is the basic unit of framework structure in PMO-M and ${ }^{13} \mathrm{C}$ CP MAS NMR confirmed that the ethane 

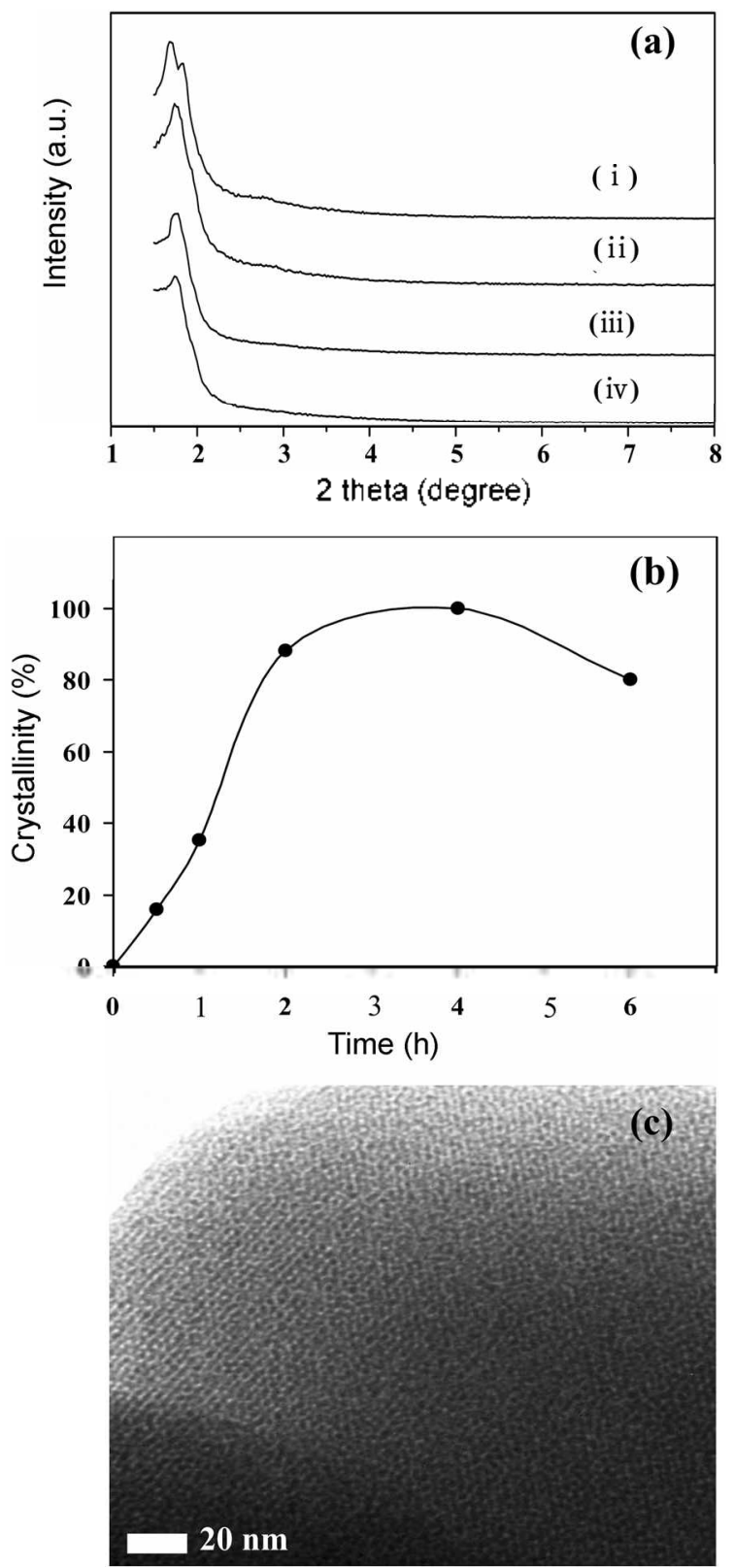

Figure 1. (a) X-ray diftraction pattens of PMO samples: (i) PMOC: (ii)(iii)(iv) $\mathrm{PMO}-\mathrm{M}$ samples prepared at 95,115 , and $135^{\circ} \mathrm{C}$ for $4 \mathrm{~h}$, (b) Crystallinity curve of the PMO-M samples synthesied at $115^{\circ} \mathrm{C}$, (c) TEM image of the PMO-M synthesized at $95^{\circ} \mathrm{C}$ for 4 h.

fragments of the precursor were not cracked during hydrolysis process. ${ }^{8,24}$ The ${ }^{29} \mathrm{Si}$ cross-polarization (CP) MAS NMR spectrum of the PMO-M sample in Figure 3(a) shows two signals at -56.8 and $-66.9 \mathrm{ppm}$ which are assigned to $\mathrm{Si}$ species covalently bonded to carbon atoms $[-56.8 \mathrm{ppm}$. $\mathrm{SiC}(\mathrm{OH})(\mathrm{OSi})_{2} ;-66.9$ ppm. SiC-(OSi) , respectively]. The ${ }^{13} \mathrm{C}$ CP NMR spectrum of the sample in Figure $3(\mathrm{~b})$ shows one signal at $4.8 \mathrm{ppm}$, which is assigned to an ethane fragment sandwiched by silicons $\left(\mathrm{Si}-\mathrm{CH}_{2} \mathrm{CH}_{2}-\mathrm{Si}\right.$ ). The $\mathrm{SiO}_{4}$ species such as $\mathrm{Si}(\mathrm{OH})(\mathrm{OSi})_{3}$ and $\mathrm{Si}(\mathrm{OSi})_{4}$. whose signals are usually observed between -90 and -120 ppm were absent. No carbon signal due to surfactant (CTMACl) is

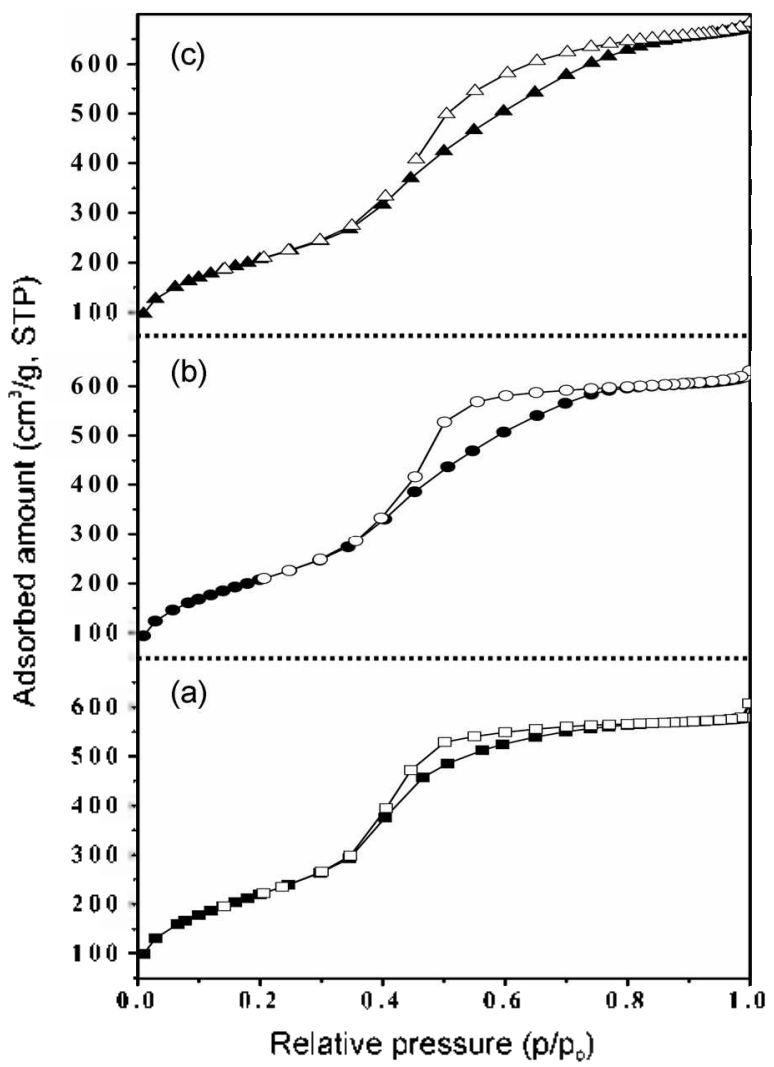

Figure 2. $\mathrm{N}_{2}$ adsorption-desorption isotherms of PMO-M samples prepared at (a) $95^{\circ} \mathrm{C}$, (b) $115^{\circ} \mathrm{C}$, (c) $135^{\circ} \mathrm{C}$ for $4 \mathrm{~h}$.

Table 1. Textural properties of PMO-M samples

\begin{tabular}{ccccc}
\hline $\begin{array}{c}\text { Sample } \\
\text { No. }\end{array}$ & $\begin{array}{c}\text { Synthesis } \\
\text { condition }\end{array}$ & $\begin{array}{c}\text { Pore size } \\
(A)\end{array}$ & $\begin{array}{c}\text { Pore vol. } \\
\left(\mathrm{cm}^{3} / \mathrm{g}\right)\end{array}$ & $\begin{array}{c}\text { Surface area } \\
\left(\mathrm{m}^{2} / \mathrm{g}\right)\end{array}$ \\
\hline 1 & $95^{\circ} \mathrm{C}-4 \mathrm{~h}$ & 32 & 0.94 & 769 \\
2 & $115^{\circ} \mathrm{C}-4 \mathrm{~h}$ & 36 & 0.99 & 776 \\
3 & $115^{\circ} \mathrm{C}-6 \mathrm{~h}$ & 56 & 0.93 & 490 \\
4 & $135^{\circ} \mathrm{C}-4 \mathrm{~h}$ & 39 & 1.99 & 741 \\
5 & $95^{\circ} \mathrm{C}-21 \mathrm{~h}(\mathrm{H})^{*}$ & 28 & 0.79 & 799 \\
\hline
\end{tabular}

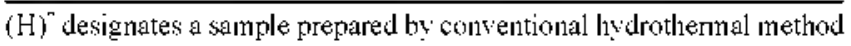

observed. suggesting complete removal of surfactant from the as-synthesized PMO-M.

TGA of PMO-M was conducted in a nitrogen flow (not shown) and the weight of PMO-M deceased about $6 \%$ at temperature below $150^{\circ} \mathrm{C}$ due to the release of solvent used for the surfactant extraction. Residual surfactant left inside the pores decomposed to $400^{\circ} \mathrm{C}$. Then. the decomposition of $\mathrm{CH}_{2}-\mathrm{CH}_{2}$ groups in their framework gradually appeared at temperature above $400^{\circ} \mathrm{C}$ and ca. 15 wt \% loss was detected at $800^{\circ} \mathrm{C}$. This trend is essentially in agreement with the the results reported by Kruk et $\mathrm{al}^{9}$

Figure 4 shows the SEM images and particle size distribution of the PMO-M syinthesized at 95,115 , and $135^{\circ} \mathrm{C}$. respectively. They all have spherical shape and are smaller in size than PMO-C $(8.0 \mu \mathrm{m})$ prepared by conventional heating in (a). The arerage particle size of PMO-M was 2.2 im when syinthesized at $95^{\circ} \mathrm{C}$ and $1.5 \mu \mathrm{m}$ at $115^{\circ} \mathrm{C}$ and 135 
(a)

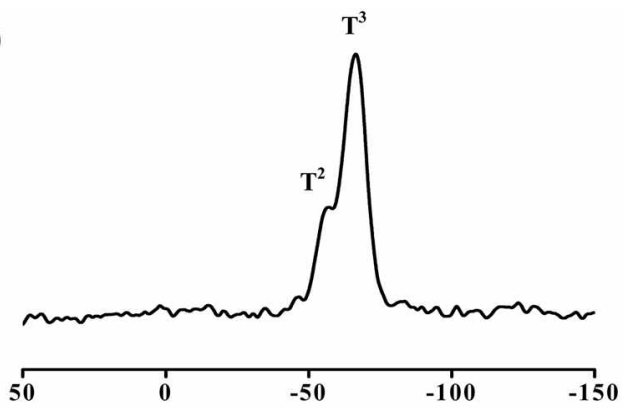

(b)

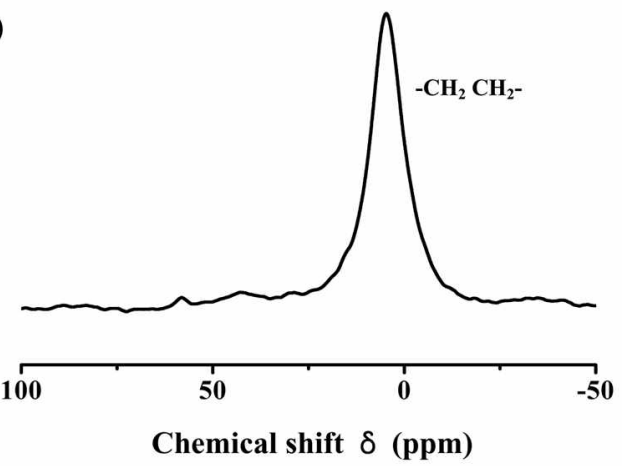

Figure 3. ${ }^{24} \mathrm{Si}$ (a) and ${ }^{13} \mathrm{C}$ (b) CP MAS NMR spectra of the PMOM sample.
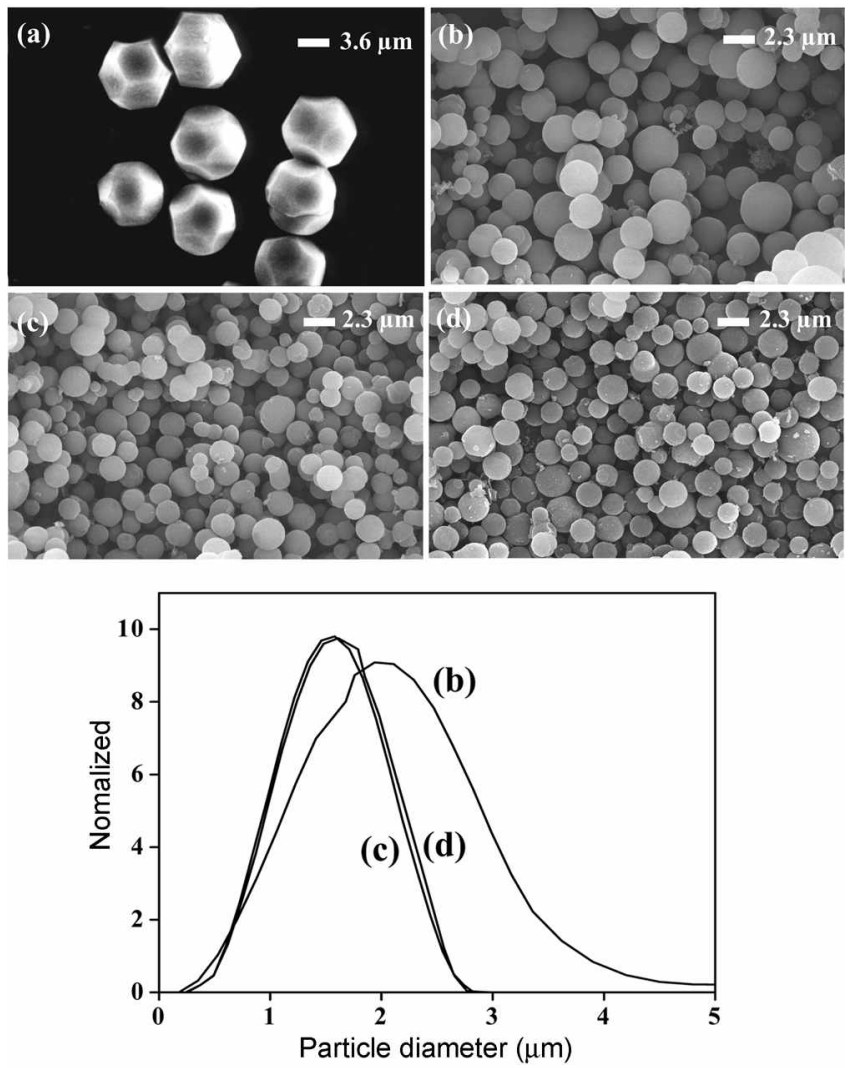

Figure 4. SEM inages and particle size distributions of PMO samples (a) $95^{\circ} \mathrm{C}$ (PMO-C), (b) $95^{\circ} \mathrm{C}$ (PMO-M) (c) $115^{\circ} \mathrm{C}$ (PMO-M), and (d) $135^{\circ} \mathrm{C}$ (PMO-M) for $4 \mathrm{~h}$.

${ }^{\circ} \mathrm{C}$. PMO-M synthesized at $115^{\circ} \mathrm{C}$ and $135^{\circ} \mathrm{C}$ demonstrated narrower size distribution than that prepared at $95^{\circ} \mathrm{C}$. Syn-

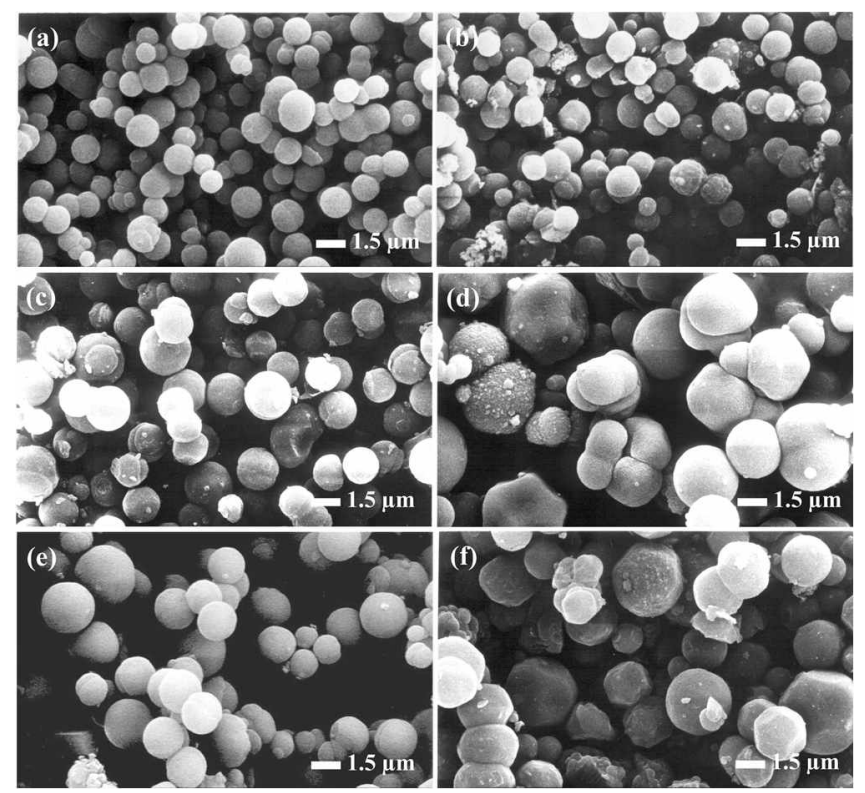

Figure 5. SEM images of PMO-M samples by the control of heating power maximum $950 \mathrm{~W}$ at $2450 \mathrm{MHz}$ ) at $115^{\circ} \mathrm{C}$ for $4 \mathrm{~h}$; (a) $100 \%$, (b) $50 \%$, (c) $25 \%$, (d) $15 \%$ of maximum power, (e) $100 \%$ microwave heating $1 \mathrm{~h}+$ hydrothermal $21 \mathrm{~h}$, (f) $100 \%$ microwave power after an addition of a swelling agent (mesitylene: surfactant $=2$ ).

thesis time up to $6 \mathrm{~h}$ at $115^{\circ} \mathrm{C}$ did not affect the morphology of the synthesized particles nor changed the size distribution significantly, but the textural properties shown in Table 1 indicated that prolonged microwave irradiation is not desirable.

Finally, heating rate to the target synthesis temperature of $115^{\circ} \mathrm{C}$ was controlled by adjusting nicrowave power and its effect on particle size was examined. Once the target temperature is reached. power level was adjusted to $50 \%$ full power and irradiation was kept for further $4 \mathrm{~h}$. At the maximum power level. it took less than $1 \mathrm{~min}$ to reach $115^{\circ} \mathrm{C}$. but as the power level is dropped. it took progressively longer to reach the target temperature. We envisaged that this drop in heating rate would decrease the nucleation rate and the nutrient left in the substrate mixture would be supplied to the nuclei to grow. SEM image of the corresponding PMO-M samples are shown in Figure 5. When microwave heating power is $100 \%$ or $50 \%$ of the full power. no clearly detectable changes in particle size were observed in (a) and (b). However. particle size has gradually grown when it comes to the PMO-M samples synthesized with powers below $50 \%$ of the full power. Deterioration in spherical morphologies and loss in particle size distribution were also observed in (c) and (d). Combination of microwave heating for $1 \mathrm{~h}$ with full power followed by conventional heating for $21 \mathrm{~h}$ produced PMO with increased particle size in (e). By adding a swelling-agent. mesitylene to the substrate. PMO-M particle size has grown but crystal surface became increasingly faceted as in (f).

The separation performances of the PMOs samples prepared were compared in Figure 6. PMO-M synthesized at 95 

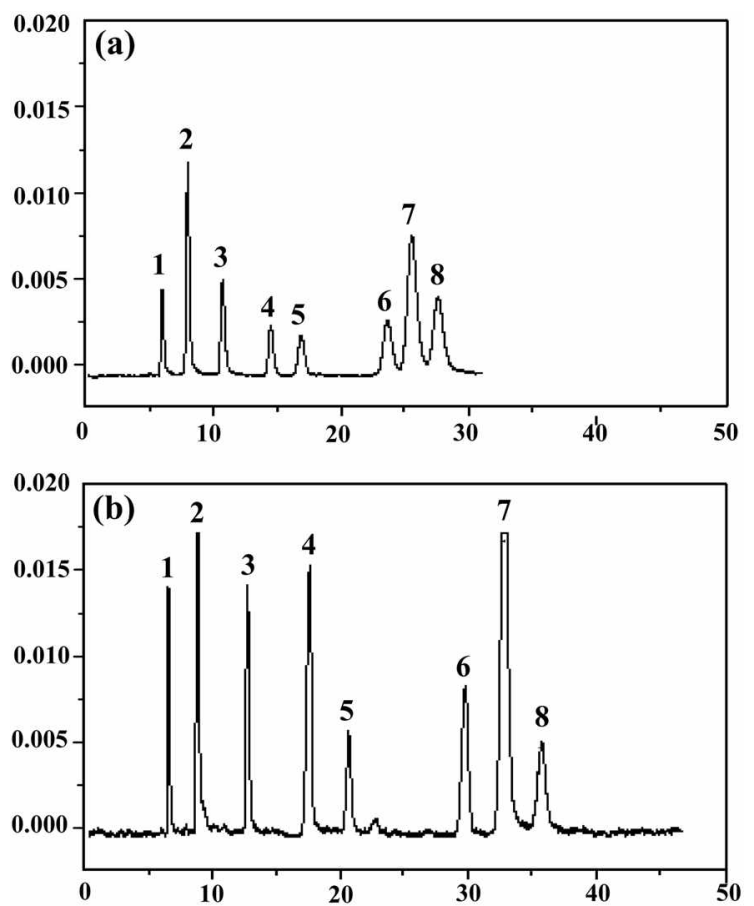

Figure 6. Chromatograms obtained in $80 / 20 \mathrm{v} / \mathrm{v} \% \mathrm{MeOH} / \mathrm{H}_{2} \mathrm{O}$ at the flow rate of $10 \mathrm{~mL} / \mathrm{min}$ with different stationary phases: (a) PMO-C, (b) PMO-M synthesized at $95^{\circ} \mathrm{C}$ for 4 h by microwave heating method: Solutes 1; 4-Methoxyphenol, 2; Acetophenone, 3; Ethylbenzoate, 4: Ethylbenzene, 5: Acenaphthylene, 6; Acenaphthene, 7; Phenanthrene, 8: Anthracene.

${ }^{\circ} \mathrm{C}$ for $4 \mathrm{~h}$ by microwave heating demonstrated superior separation ability to that of PMO-C; peaks are better resolved and. in particular. solutes 6.7. and 8 are well separated with PMO-M in (b). This enhancement in separation is because of the PMO-M having smaller particle size in spherical morphology. Table 1 also showed that PMO-M particles have wider pores accompanied by larger pore volume than PMO-C. which are the attributes for enhanced separation.

Catalytic performance results of the Ti-grafted PMOs in cyclohexene epoxidation are summarized in Table 2 . The UV-Vis spectra for samples containing $2 \%$ of Ti grafted to PMO-M are given Figure 7. The band at $c a .220 \mathrm{~nm}$ is associated with isolated Ti(IV) framework sites fundamentally similar in character to those in TS-1. The shoulder at $270 \mathrm{~mm}$ corresponds to partially polymerized hexacoordinate $\mathrm{Ti}$ species. and a small amount of Ti-O-Ti clusters are

Table 2. Cyclohexene epoxidation by Ti-grafted hybrid PMO samples

\begin{tabular}{lcccccc}
\hline \multirow{2}{*}{ Samples } & Conversion & \multicolumn{5}{c}{ Selectivity (\%) } \\
\cline { 3 - 7 } & $(\%)$ & oxide & 1 -ol & 1-one & diol & ethers \\
\hline Ti-PMO-C & 10.1 & 9 & 11 & 30 & 0 & 50 \\
Ti-PMO-M & 13.9 & 5 & 7 & 24 & 4 & 60 \\
\hline
\end{tabular}

Reaction was carried out at $333 \mathrm{~K}$ for $3 \mathrm{~h}$ using 33 mmol substrate, 20 mmol $\mathrm{H}_{\Sigma} \mathrm{O}_{乏}(30$ wt $\% 0) .20 \mathrm{~mL}$ acetonitrile and $0.2 \mathrm{~g}$ catalyst: $\mathrm{Ti}(\mathrm{Si}-\mathrm{Ti})=$ $2 \mathrm{~mol}^{\mathrm{io}}$

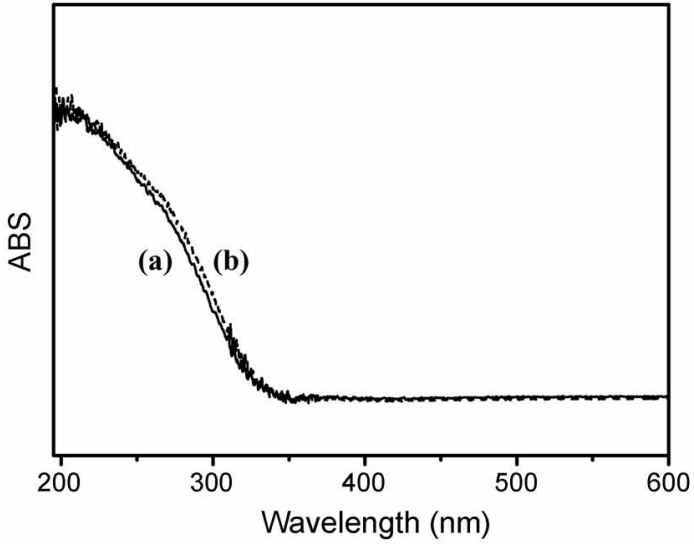

Figure 7. UV-Vis spectra containing $2 \%$ of Ti grafted PMO sample: (a) Ti-PMO-M, (b) Ti-PMO-C.

suspected to co-exist with the isolated Ti sites in samples. The catalytic reaction was carried out using $\mathrm{H}_{2} \mathrm{O}_{2}$ as an oxidant in acetonitrile solvent, and Ti-grafted PMO-M achieved higher cyclohexene conversion (13.9\%) than by $\mathrm{PMO}-\mathrm{C}$ after Ti-grafting ( $10.1 \%)$. The product distributions were mostly the same. With microwave heating. it was possible to synthesize smaller PMO particles via promoting nucleation process. The material with smaller particle size diminish diffusion resistance against reactants/products for contacting/ leaving catalytic sites in liquid phase reactions. and resulted in an improvement in catalytic performance.

\section{Conclusions}

An organic-inorganic lyybrid mesoporous material, PMOM. with ethane groups uniformly incorporated to a silica framework was synthesized using microwave heating. PMO$\mathrm{M}$ with smaller and uniform particle size was synthesized because rapid microwave heating promotes nucleation and simultaneously reduction in sy'nthesis time was achieved. Particle size of the PMO-M was found in a range of 1.5 to $2.2 \mu \mathrm{m}$. and further control in particle size could be achieved by adjusting the microwave heating power at the nucleation stage. PMO-M demonstrated improved separation capacity in a reversed phase HPLC as a stationary phase and also showed better catalytic performance in liquid phase cyclohexene epoxidation reaction compared with a PMO-C prepared by conventional oven heating.

Acknowledgements. This work was supported by Inha University Research Grant. HPLC analysis by Prof. W. J. Cheung in the Chemistry Department is gratefully acknowledged.

\section{References}

1. Kresge. C. T.: Leonowicz. M. E.: Roth. W. J.: Vartuli. J. C.: Beck. J. S. Natwe 1992.359,710.

2. Beck. J. S.: Vartuli, J. C.; Roth. W. J.; Leonowicz. M. E.; Kresge. C. T.: Schmitt, K. D.: Chu, C. T. W.: Olson, D. H.: Sheppard. E. W: McCullen. S. B.: Higgitss. I. B.: Schlenker. . J. L. J. Ant. 
Chem. Soc. 1992. Ht. 10834

3. Lim. M. H.: Blnford. C. F.: Stein. A. J. An. Chem Soc. 1997. 119. 4090 .

4. Fowler. C. E.: Lebeal. B.: Mann. S. Chem. Commm. 1998. 1825 .

5. Baney: R. H: Itoh. M.: Sakakibara. A: Suzuki. T. Chem. Ren: 1995. 95.1409 .

6. Loy. D. A.: Shea. K. J. Chem. Rev 1995. 95. 1431.

7. Inagaki. S.: Guan. S.: Fukushima. Y.: Ohsuna. T.: Terasaki. O. $J$. Am. Chem. Soc. 1999. 121,9611.

8. Guan S: Inagaki. S: Onsuna, T: Terasaki. O. J. Am. Chem. Soc. 2000, 122,5660

9. Kruk. M.: Jaroniec. M.: Guan. S.: Inagaki. S. J. Phns. Chent. B 2001. 105.681

10. Asefa. T:: MacLachlan. M. J.: Coombs. N.: Ozin. G. A. Nature 1999, 402,867 .

11. Yoshina-Ishii. C: Asefa. T.: Coombs. N.: MacLachlan, M. I.: Ozin. G. A. Chem. Conmm. 1999, 2539.

12. Inagaki. S.: Guan. S.: Ohsuna. T.: Terasaki. O. Nature 2002 . th6. 304.
13. Kapoor. M. P.: Yang. Q.: Inagaki. S. J. Am. Chent Soc. 2002. 12t. 15176

14. Kapoor. M. P.: Inagaki. S. Chem. Mater 2002. 14. 3509

15. Park, S. S.: An. B.: Ha. C. S. Mficropor Hesopor Mater 2008. in press.

16. Muth. O.: Schellbach. C.: Fröba. M. Chem. Commun $2001,2032$.

17. Melde. B. J.: Holland. B. T.: Blanford. C. F.: Stein. A. Chen Mater: 1999. 11.3302.

18. Zhu. H.: Tones. D. T.: Zajac. J.: Dutartre. R.: Rhomari. M: Roziere, J. Chem M Hater $\mathbf{2 0 0 2}, 1+4886$.

19. Zhao. J. P. Cundy. C. Dwyer. J. Stud Surf. Sci. Catal 1997, 105. 181 .

20. Afrat. A.: Jasen. T. C.: Ebaid. A. R.: Van Bekkum. H. Zeohites 1997.3.162.

21. Meng. X.: Xu. W.: Pang. W. Chim Chent Lett. 1992. 3. 69.

22. Kang. K. K.: Park. C. H.: Ahn, W. S. Catal. Lett. 1999, 59.45.

23. Jiang. N. Choi, K. M.: Han. S. C.: Koo, J. B.: Park, S. E. Stud. Surf. Sci. Catal. 2007, 165,901.

24. Kim. D. J.: Chung. T. S.: Ahn1. W. S.: Kang. G. W.: Cheong. W. J Chent. Lett. 2004. 33. 422. 